\title{
COMPARATIVE ANALYSIS BETWEEN ANP AND ANP- DEMATEL FOR SIX SIGMA PROJECT SELECTION PROCESS IN A HEALTHCARE PROVIDER
}

\section{ABSTRACT}

This paper presents an ANP technique applied to identify and priori- tize Six Sigma projects for healthcare providers whose results allow selecting the project that ensures the maximum financial benefits for the healthcare com- pany. First, the Six Sigma evaluation model is determined, then the criteria weights are established by ANP (Analytic Network Process) and finally, results from ANP and ANP- DEMATEL (Decision Making Trial and Evaluation Labo- ratory) are compared. The results show a better decision making performance for ANP-DEMATEL. An empirical case from healthcare sector is presented, showing the effectiveness of the proposed technique. 